\title{
GLIOMA INFILTRATIVO DO TRONCO CEREBRAL SIMULANDO ENCEFALITE
}

\author{
Roberto Melarigno Filito * \\ Aloysio Matros Pimenta **
}

O registro dêste caso se justifica especialmente pelas dificuldades do diagnóstico etiopatogênico -- pelo menos nas fases iniciais da doença de um processo cuja topografia era bem evidente. Trata-se de uma criança, cujas primeiras manifestações mórbidas, configurando um quadro infeccioso, com febre e narcolepsia, orientavam o diagnóstico para encefalite. Entretanto, a evolução veio demonstrar que a síndrome, fàcilmente localizável, dependia de um glioblastoma multiforme infiltrativo da protuberância e do bulbo. Realmente, o diagnóstico diferencial entre a gliomatose do tronco cerebral e a encefalite tem importância, sobretudo para o prognóstico.

1. G., con 7 anos de idade, branca. A paciente foi examinada, pela primeira vez, por um de nós (R.M.F.), em sua residência, em 21 junho 1949. Referianı os progenitores que as primeiras manifestações mórbidas se haviam iniciado aproximadamente um mês antes, por sonolência inabitual e exagerada, adormecendo em plena aula, o que the valera repreensĩes da professora. Êsses sintomas se acentuaraun e, nessa ocasião, foi verificada temperatura de aproximadamente $38^{\circ} \mathrm{C}$, a qual se manteve por diversos dias. Nos dias 19 e 20 de junho, o quadro clínico, até então considerado pelo clínico da família como simples infecção gripal, se agravou ràpidamente. A criança passou a apresentar vómitos contínuos, vertigens rotatórias a impossibilitar a permanência na posição de pé, e, pouco a pouco, entrou em estado de

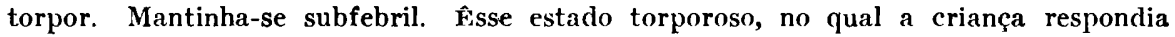
a custo a nossas solicitações, naturalmente, não permitiu exame neurológico muito rigoroso. Conseguimos objetivar uma paresia dos membros esquerdos, sobretudo do inferior, com hiperreflexia profunda, sinais de Rossolimo e Mendel-Bechterew, clono, trepidações e franco sinal de Babinski. Por outro lado, à direita, notamos paresia do nervo facial, do tipo periférico, e paralisia do reto externo ocular. Não havia a menor referência a diplopias. Ao olhar lateral, principalmente para o lado direito, aparecia nistagmo horizontal. Năo havia queixa de cefaléia nem de perturbações visuais. $O$ exame oftalmoscópico Acmonstrou papilas inteiramente normais. Pulso ligeiramente taquicárdico; bulhas cardíacas, normais.

Destarte, firmamos o diagnóstico provisório de síndrome de Millard-Gübler, por lesão protuberancial direita. $O$ início por surtos narcolépticos e por febre nos suge-

Trabalho apresentado ao Departamento de Neuro-Psiquiatria da Associação Paulista de Medicina, em 7 novembro 1949. Tolosa).

* Assistente de Neurologia da Fac. Med. da Univ. de São Paulo (Prof. A.

** Neurocirurgião do Serviço de Neurologia da Escola Paulista de Medicina (Prof. Paulino W. Longo). 
riu como mais provável causa etiológica, um processo infeccioso; seria, pois, uma mesocefalite a vírus.

Mediante tal diagnóstico, instituímos medicação antinfecciosa $e$ vitamina $B_{1}$. Exame do líqüido cefalorraquidiano: punção suboccipital, deitada; liquor límpido e incolor; citometria 0,4 células por $\mathrm{mm}^{3}$; proteínas totais $0,10 \mathrm{~g}$ por litro; cloretos $7,4 \mathrm{~g}$ por litro; glicose $0,66 \mathrm{~g}$ por litro; reações das globulinas negativas; reação de benjoim 00000.00000.00000.0; reação de Takata-Ara negativa; reações de Wassermann, Steinfeld, desvio de complemento para cisticercose, Meinicke e Eagle negativas (Dr. Oswaldo Lange, 21-6-1949).

Evolução - Revimos a criança no dia 23 de junho. Seu estado geral melhorara muito, estava bem lúcida, de modo a permitir um exame neurológico mais preciso. $\mathrm{O}$ estudo dos aparelhos circulatório e respiratório foi completamente negativo. Ausência de gânglios linfáticos enfartados. Não conseguia ficar de pé sem apôio e, desde que o membro inferior esquerdo tocava ao solo, surgiam trepidações epileptóides. Fôrça muscular diminuída nos membros esquerdos, com positividade das manobras de Mingazzini e Barré. Manobras deficitárias nos membros superiores, pràticamente normais. Embora o déficit motor prejudicasse em parte o estudo da coordenação muscular, tivemos a impressão de certa ataxia do tipo cerebelar nos membros esquerdos. A direita, embora em grau menos intenso que no lado oposto, verificava-se também discreta inccordenação, nåo influenciável pelo contrôle visual. De ambos os lados, pelas provas gráficas, discreta dismetria. Entretanto, tão moderados eram êsses elementos da síndrome cerebelar que, em razão da pequena idade da criança, não nos convenceram totalmente. O tono muscular predominava em intensidade francamente no lado esquerdo em relação ao direito. $\boldsymbol{A}$ esquerda, persistiam todos os sinais piramidais de libertação: hiperreflexia profunda, clono, trepidações, sinal de Babinski. Sensibilidade táctil, térmica e dolorosa, artrestésica e vibratória íntegras em todo o corpo, inclusive na face. Sensibilidade da córnea igual de ambos os lados. A paresia facial periférica direita persistia, embora em grau menor que o verificado no exame anterior. Paralisia do nervo abducente direito, sem diplopia. Nítida hipoacusia em OD. Nistagmo horizontal espontâneo ao olhar extremado para a direita e para a esquerda. Vertigens do tipo rotatório à movimentação voluntária ou passiva da cabeça. Ausência de zumbidos nos ouvidos, de disfagia ou de disartria. Em vista do estado geral clesfavorável da criança, dispensamos a solicitação de exame instrumental do aparêlho vestibular.

Em virtude de uma sínảrome composta de sinais nítidos dos nervos cranianos VI, VII e VIII em um lado onde havia tambén sinais - embora muito discretos de ataxia cerebelar, acompanhados de hemiplegia contralateral, surgiu a hipótese de um tumor do ângulo pontocerebelar direito. Apesar da ausência persistente de qualquer sinal de hipertensão intracraniana, encaminhamos a paciente ao Dr. Celso lereira da Silva, com a solicitação de radiografias do crânio nas posições de irrente, perfil e de Stenvers; essas radiografias foram totalmente normais. Prescrevemos então, ao lado da medicação antinfecciosa pelos iodetos e salicilados, a aureomicina ( 2 cápsulas de $250 \mathrm{mg}$, diárias) e radioterapia profunda da fossa posterior. Após a primeira aplicação de radioterapia, dosada a 100 r., houve certo agravamento do estado geral; insistimos na terapêutica e, depois das subsequientes aplicaçôes, sempre na mesma dosagem, o estado geral, principalmente o torpor, melhorou bastante. A sintomatologia focal não se modificou essencialmente.

No dia 13 de julho, solicitamos conferência com neurologista da Capital e seu parecer coincidiu com o nosso: mesocefalite a vírus. Durante um mês, a sintornatologia permaneceu pràticamente inalterada. Em 13-8-49, novo exame de líqüido ce- 
falorraquidiano: punção suboccipital, deitada; pressão inicial 14; líquor limpido e incolor; citometria 0,t células por $\mathrm{mm}^{3}$; cloretos $7,1 \mathrm{~g}$ por litro; glicose $1 \mathrm{~g}$ por litro; reações das globulinas e coloidais negativas; uréia $0,25 \mathrm{~g}$ por litro (Dr. $O$. Lange). Além da elevação do teor da glicose, corroborava muito fortemente o diagnóstico etiológico do processo a vírus, o aparecimento de um novo sinal que perdurou por cêrca de uma semana: movinentos coreiformes no hemicorpo direito. $O$ quadro térmico havia-se normalizado logo após a instalação dos sinais focais.

Apesar de nunca havermos notado modificações do fundo de ôlho, pedimos um exame neurocular (Dr. Paulo Braga Magalhães): pupilas isocóricas, reflexos pupilares normais; papilas de coloração e níveis normais; ausência de alterações de artérias e veias retinianas; paralisia do músculo reto externo direito, sem diplopia. Em fins de junho, havia completado 800 r. de radioterapia e seu estado geral era satisfatório, embora a sintomatologia focal permanecesse inalterada.

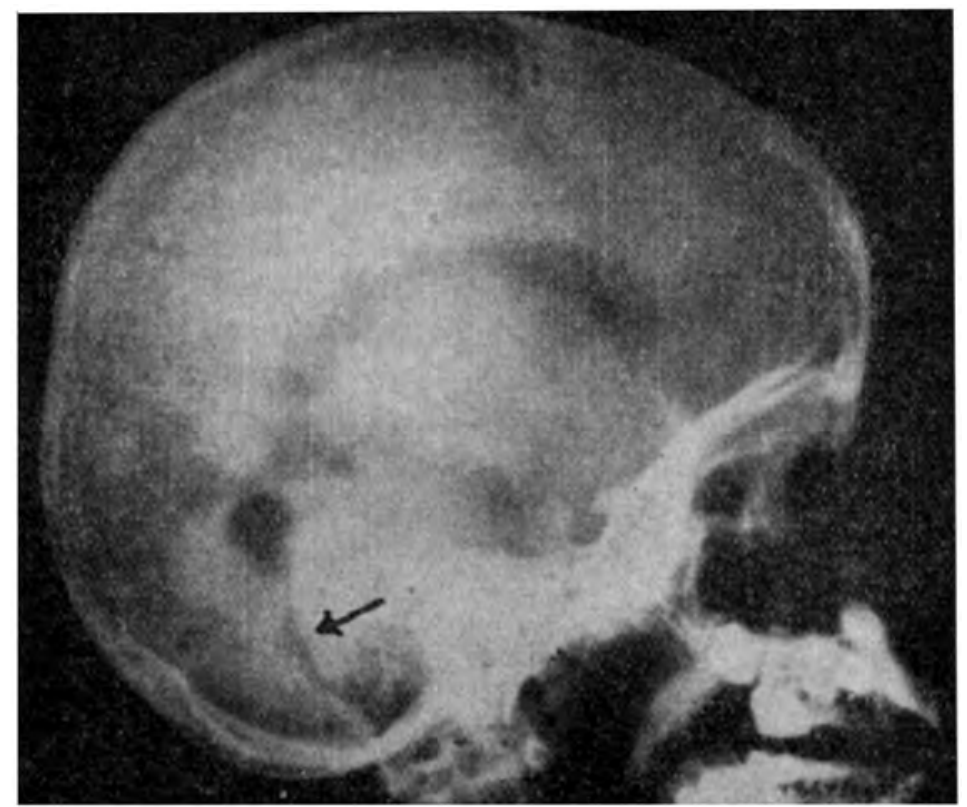

Fig. 1 -- Caso I. G. Pneumoventriculografia em perfil esquerdo. Observar o deslocamento dorsal do sistema aqueduto-quarto ventrículo, que descreve um arco.

No dia 3 de agôsto, por três vêzes, apresentara, durante a noite, movimentos dos membros direitos que, pelia descrição, pareciam ser convulsões bravais-jacksonianas. Por três ou quatro noites, movimentos semelhantes se repetiram, havendo finalmente cedido pelo emprêgo do gardenal. Nessa ocasião, surgiram disfagia e disartria discretas. Sùbitamente, no dia 14 de agôsto, o quadro clínico voltou a se ayravar: febre, torpor intenso, vómitos e queda do estado geral. Por sugestão do médico da família, foi ouvida a opiniảo de outro co-autor dêste reguistro (A.M.P.). Diante da resistência ao tratamento e da longa evolução do caso, decidimos apurar a exis- 
tência de um tumor da fossa posterior, apesar da ausência de hipertensão intracraniana. Para tal fim, foi realizada a pneumoventriculografia em 20-8-49, que demonstrou ligeira hidrocefalia simétrica supratentorial; nas chapas de perfil, a conjunto aqueduto-IV ventrículo descrevia um arco significativo de deslocamento dorsal do sistema. Impressão ventriculográfica: tumor do tronco cerebral (fig. 1).

o líqüido ventricular demonstrou: líquor ligeiramente turvo, límpido e incolor após centrifugação; hemácias integras; proteínas totais $0,05 \mathrm{~g}$ por litro; cloretos $7,5 \mathrm{~g}$ por litro; glicose $0,7 \mathrm{~g}$ por litro; reações para globulinas negativas; reação do benjoim 22000.00000.00000.0; reação de Takata-Ara negativa; reação de Wassermann negativa; uréia 0,15 $\mathrm{g}$ por litro; exame baterioscópico pelo Gram e Ziehl, negativo.

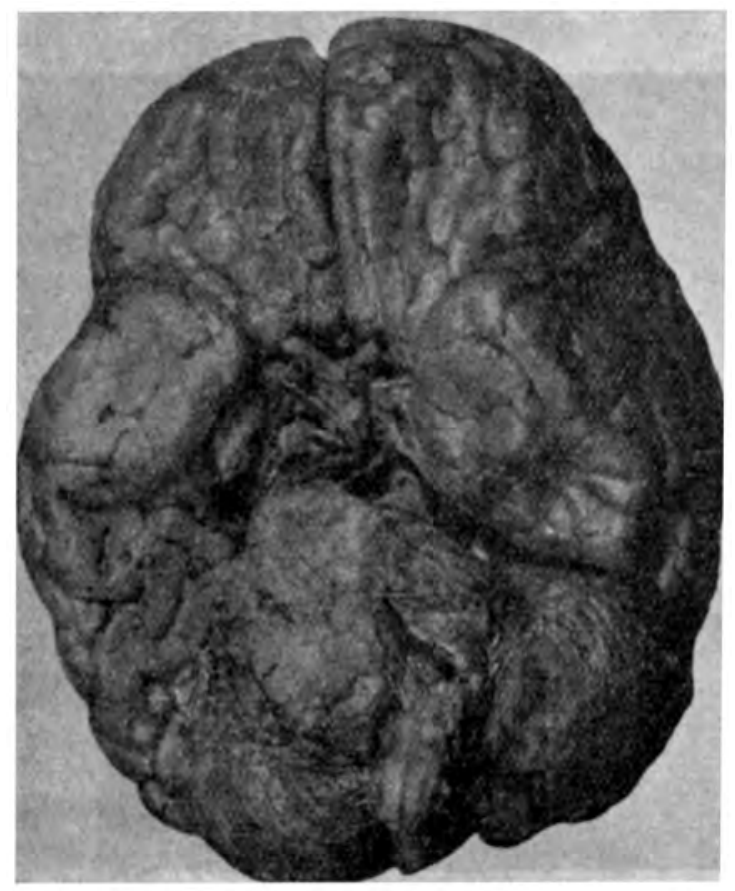

Fig. \& - Caso I. G. Superfície inferior do encéfalo. Observar a grande formação tumoral do rombencéfalo, deformando a superfície inferior do hemisfério cerebelar direito e desviando para o lado esquerdo a ponte e o bulbo.

Operação - Nesse mesmo dia, na possibilidade do tumor ser extrínseco e, mesmo com a indicação de uma descompressiva local, foi proposta e decidida a craniotomia da fossa posterior. A craniectomia suboccipital mostrou a existência de um tumor infiltrativo da protuberância e do bulbo, produzindo grande dilatação dêste último segmento. $\Lambda$ fím de se verificar sua possível natureza cística, foi feita uma punção. Diante do resultado negativo da punção e da localização do tumor, não foi 
realizada biópsia e a intervenção, dada como encerrada. A paciente não apresentou melhoras neurológicas; seu estado foi gradativamente decaindo. Nos pós-operatório cirúrgico ocorreu una fístula liquórica. Nos últimos dias de vida, a paciente, que até então se apresentara lúcida, começou a entrar em torpor, que se acentuou, entrando em coma e falecendo no dia 12 de setembro de 1949.

Autópsia - Foi conseguida a retirada do encéfalo. Já macroscòpicamente observava-se um tumor infiltrativo, invadindo a protuberância e o bulbo. $O$ neoplasma produzia saliência no lado direito, que explicava a sintomatologia pontocerebelar. No aspecto externo do encéfalo, notava-se grande formação tumoral, situada no rombencéfalo, deformando a superfície inferior do hemisfério cerebelar direito e desviando para o lado esquerdo a ponte $\mathrm{e} o$ bulbo. $O$ mesencéfalo estava pràticimente na posição normal (fig. 2). A formação tumoral, ao exame externo, apresentava volume de aproximadamente $60 \mathrm{~cm}^{*}(6 \times 5 \times 2 \mathrm{~cm})$. Ao corte transversal (fig. 3)

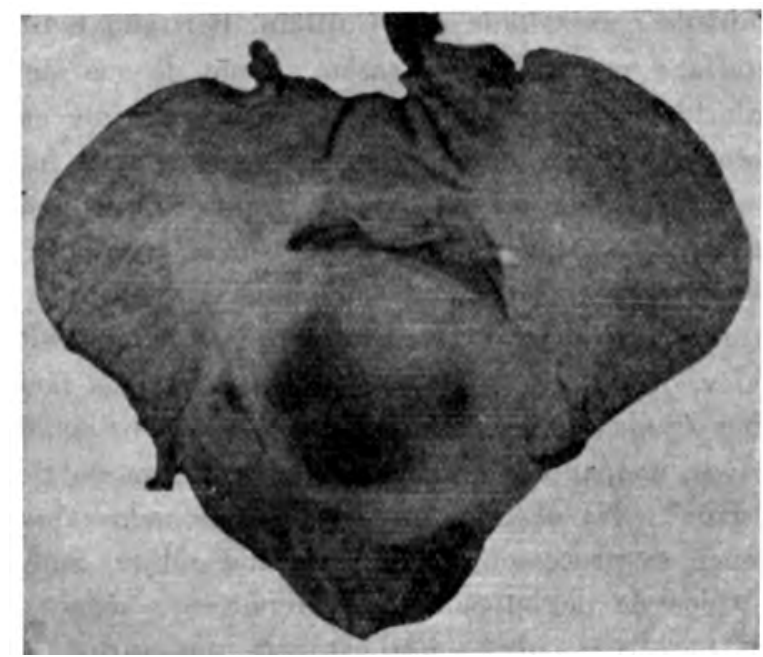

Fig. 3 - Caso I. G. Corte transversal do rombencéfalo. abrangendo a formação tumoral, un glioblastoma multiforme.

essa formação neoplástica apresentava uma estrutura central, clara e resistente, situada no teto do quarto ventrículo e uma substância cinzenta avermelhada, mais mole, situada mais superficialmente. Na periferia do tumor observava-se uma verdadeira camada, de $1,5 \mathrm{~cm}$ de espessura por $+\mathrm{cm}$ de comprimento, que destruia o tecido cerebelar. Aos cortes frontais do cérebro, verificava-se dilatação dos cornos anteriores de ambos os ventrículos laterais, ao passo que o restante dos ventrículos laterais apresentava nítida assimetria : o corpo e os cornos posterior e temporal do ventrículo esquerdo pràticamente normais, enquanto que, à direitr, essas formações estavam muito dilatadas, principalnente nos cornos posterior e inferior. $O$ côrno posterior do ventrículo direito apresentava uma solução de continuidade tissular. $O \quad 3.0^{\circ}$ e $4 .^{\circ}$ ventrículo se achavam também dilatados. O estudo histopatológico da reoplasia, realizado pelo Dr. Walter E. Maffei, revelou tratar-se de glioblastoma multiforme. 


\section{COMENTARIOS}

Neste caso se comprova a grande dificuldade, senão a impossibilidade, de se estabelecer precocemente o diagnóstico diferencial entre o tumor infiltrativo do tronco encefálico e a mesocefalite a vírus. Sôbre êsse pưito desejamos chamar particularmente a atenção. Realmente, um paciente jovem com um quadro complexo de sintomas pontobulbares não sistematizados, havendo-se iniciado com as aparências de uma infecção, sugere naturalmente o diagnóstico de uma encefalite. Nosso caso exemplifica como êsse diagnóstico é enganoso e como pode o quadro clínico ser causado por um glioma infiltrativo.

Essa dificuldade é ressaltada por Guillain, Bertrand e Gruner, em sua recente monografia e se explica em razão mesmo de sua sintomatologia e de suas particularidades clínicas: incidência principalmente em crianças ou em jovens, ausência habitual de hipertensão intracraniana, início por vêzes febril, com evolução aguda ou subaguda. Segundo êstes autores "1, "é incontestável que, em sua primeira fase, a afecção se apresenta com tôdas as aparências de uma encefalite, ou antes, de uma mesocefalite aguda; o estado febril ou subfebril orienta também para êsse diagnóstico. Após várias semanas ou vários meses, o diagnóstico torna-se mais fácil. Com efeito, nas encefalites agudas ou subagudas do mesocéfalo, os sinais são freqüentemente regressivos, enquanto que, na gliomatose difusa do tronco cerebral, êles são regressivos". Na observação 3 dos mencionados autores francêses, o início da doença se processou por hipertermia súbita, atingindo a $40^{\circ} \mathrm{C}$, cefaléia e distúrbios da deglutição. Esses fenômenos cederam e posteriormente surgiram paralisias, que ainda evoluem por surtos. Tratava-se de gliomatose difusa, evocando antes a sintomatologia de esclerose em placas aguda ou de uma infecção a vírus, que a de um tumor cerebral.

Merecem citação outros casos da literatura, em que o início aparentemente infeccioso conduziu a falsos diagnósticos etiológicos. Assim, Bailey ${ }^{2}$ observou 12 crianças apresentando paralisias bulbares de evolução lentamente progressiva e nas quais, "embora quase invariàvelmente o diagnóstico de encefalite ou polioencefalite tenha sido firmado durante a vida, o exame histológico revelou a existência de um tumor". Fribourg-Blanc e Masquin $^{3}$ diagnosticaram encefalite em um caso iniciado por cefaléia, diplopia e febre e no qual só posteriormente se desenvolveu uma hemiplegia. 0 estudo anátomo-patológico veio demonstrar um glioma tálamo-protuberancial. Lesné, Bertrand e Launay ${ }^{4}$, igualmente, tomaram como encefalite póscoqueluche, um caso de tumor do tronco encefálico. Vários outros exem- 
plos semelhantes são registrados na literatura, dos quais alguns vêm citados na monografia de Guillain e col.

Nosso caso devia também ser diferençado do tumor do ângulo pontocerebelar direito. Os elementos que tornavam êsse diagnóstico mais remoto eram: ausência de sinais clínicos, radiológicos e oftalmoscópicos de hipertensão intracraniana; ausência de alargamento do orifício acústico às radiografias tomadas na posição de Stenvers; ausência de zumbidos.

Em nosso caso, os distúrbios do sono, que acompanharam os primeiros sintomas, ainda mais confundiam o diagnóstico, contribuindo para orientá-lo no sentido de encefalite. Segundo frisam Guillain e col., a hipersônia é fenômeno muito raro nas gliomatoses do tronco. E' possível que, em nossa paciente, fôsse em parte responsável pelas alterações hípnicas, o tipo histológico do tumor. Realmente, como é sabido ${ }^{5}$. os glioblastomas multiformes, independentemente de sua localização, podem condicionar hipersônia ou narcolepsia (gliobastomas multiformes, formas pseudo-encefalíticas).

A ausência de fenomenologia de hipertensão intracraniana e, em particular, do edema de papila, constitui regra dos gliomas infiltrativos do tronco. Os vômitos apresentados por nossa paciente, atribuímos a distúrbios vestibulares. As perturbações piramidais, associadamente à síndrome cerebelar, são elementos primordiais, e dos mais constantes na afecção. Como acentuamos, a sensibilidade, em tôdas suas formas, estava íntegra em nosso caso; êste é também um fato comum nas gliomatoses difusas do tronco, constituindo um dos elementos diferenciais com os tumores localizados destrutivos, onde se evidenciam francos distúrbios sensitivos.

Os nervos cranianos lesados, particularmente o VI e o VII pares, são os mais afetados habitualmente na afecção: 38 vêzes sôbre 80 casos da literatura revista por Guillain, para o abducente; 20 vêzes sôbre 80 , para o nervo facial.

O líqüido cefalorraquidiano, freqüentemente normal nos casos em estudo, não demonstrou alterações no primeiro exame. Já no segundo exame, comprovou-se apreciável aumento do teor de glicose, que contribuiu ainda mais para se firmar o falso diagnóstico de encefalite.

O tipo histológico do tumor de nossa paciente, identificado como glioblastoma, não é dos mais comuns, nos casos de tumores infiltrativos do tronco. Em 85 casos recolhidos na literatura por Guillain, 45 eram constituídos por gliomas identificados. Dêstes, 17 eram astrocitomas, 18 espongioblastomas, 9 glioblastomas e 1 oligodendoglioma. Entretanto, os anátomopatologistas que estudaram o assunto insistem sôbre a variabilidade celular, emprestando maior importância ao caráter infiltrativo do tumor, com conservação dos elementos nervosos adjacentes. 


\section{BIBLIOGRAFIA}

1. Guillain, G., Bertrand, I. e Gruner, J. - Les Gliomes Infiltrés du Tronc Cérebral. Masson \& Cie., Paris, 1945, pág. 220.

2. Bayley, P. - Cit. por Guillain e col. 1, pág. 201 e 202.

3. Fribourg-Blanc e Masquin, P. - Hémiplegie alterne atribuée à encéphalite épidemique. Gliome protubérantiel. Rer. Neurol., 2:160-165, 1928.

4. Lesné, E., Bertrand, I. e Launay, $\mathrm{Cl}$. - Un cas de tumeur aigüe du mésocéphale au cours d'une coqueluche chez l'enfant. Rev. Neurol., 2:118-122 (julho) 1931.

5. Tolosa, A. e Gama, C. - Tumores paradoxais do encéfalo. A propósito de cinco casos de glioblastomas multiformes operados. Arq. Neuro-Psiquiat, 1:9-25 (junho) 1943.

Rua Xavier de Toledo 211, apto. 53 - São Paulo. 